\title{
The Mental Health Act 1983
}

\section{Views of Section 12(2)-approved doctors on selected areas of current legislation}

\author{
Vijay Bhatti, Jeremy Kenney-Herbert, Rosemarie Cope \\ and Martin Humphreys
}

\begin{abstract}
Aims and method $A$ one-in-five random sample $(n=104)$ of practitioners approved under Section 12(2) of the Mental Health Act 1983 in the West Midlands was selected. Opinions were sought on issues relating to current law and potential reform.

Results Elghty-three (80\%) doctors were interviewed. Over half (52\%) stated that the term 'mental illness' in the Act was unsatisfactory. Two-thirds (68\%) specified the need for a review of legislation relating to treatment in the community.

Clinical implications There was a diversity of views. This is likely to be reflected in the clinical practice of those interviewed. Many respondents believed that there was a need for reform in specific areas of the Act.
\end{abstract}

The Mental Health Act 1983 has been in use for more than 15 years and is currently under review. Despite periodic amendment, concerns have been expressed about potential limitations and the need for reform (Blom-Cooper et al, 1995; Law Commission, 1995; Mason \& Jennings, 1997). Recent work has shown that psychiatrists and other medical practitioners are limited in their knowledge and understanding of even fundamental aspects of current mental health legislation, suggesting the need for greater emphasis to be placed upon the law among those involved in its operation (Eastman. 1994; Humphreys, 1997).

Doctors in England and Wales may be approved by the Secretary of State under Section 12 of the Mental Health Act 1983. This gives the practitioner certain statutory powers, including that of recommending compulsory detention and treatment where necessary. With a few exceptions (Cope, 1992), there has been little examination of attitudes towards current law and the perceived need for reform. This study examined the views of a sample of Section 12(2)-approved practitioners in the West Midlands on issues concerned with involuntary hospitalisation and other matters relating to current legislation.

\section{The study}

From the list of 522 Section 12(2)-approved practitioners in the West Midlands, a one-in-five $(n=104)$ random sample was selected. A purposedesigned questionnaire was administered by face-to-face interview, with questions about various aspects of current mental health legislation, practice and attitudes to its use. Demographic data were recorded for each participant.

\section{Findings}

Of the 104 medical practitioners approached, 83 (79.8\%) agreed to participate. Twelve declined, eight could not be contacted and one had left the country. The sample consisted of 35 consultant psychiatrists, 14 senior or specialist registrars, 10 senior clinical medical officers, nine clinical assistants with five associate specialists and 10 general practitioners. Participants had been approved for a mean of nine years. In the previous six months they had made approximately 400 recommendations for compulsory detention in total.

Forty-three (52\%) said that the term 'mental illness' needed further clarification. It was described as 'vague' or 'unclear'. Various participants recommended incorporating 'subdivisional listings in the form of ICD-10' or something similar. Opinions on the usefulness of the four present legal categories and the provision for treatment of certain specific categories of disorder varied (Table 1).

Fifty-four (65\%) participants said that they would recommend detention of patients with a diagnosis of personality disorder. Fifty-two (63\%) stated that they would detain patients with personality disorder under the category of 'mental illness' rather than 'psychopathic disorder' in certain circumstances.

Thirty-eight (46\%) participants said that they would always invoke compulsory powers where a patient in their care was expressing suicidal intent and refusing voluntary treatment. 
Table 1. Views of Section 12(2)-approved doctors on current legal categories and provision of treatment

\begin{tabular}{llll}
\hline Question & Yes & No & Don't know \\
\hline Are the current legal categories useful? & $54(65 \%)$ & $29(35 \%)$ & - \\
Do they reflect the spectrum of clinical disorder? & $37(45 \%)$ & $46(55 \%)$ & - \\
Should they be more clearly defined? & $47(57 \%)$ & $36(43 \%)$ & - \\
Does the current Act make satisfactory provision for treatment of: & $27(35 \%)$ & $37(45 \%)$ & $19(23 \%)$ \\
Anorexia nervosa? & $33(40 \%)$ & $47(56 \%)$ & $3(4 \%)$ \\
Personality disorder? & $44(53 \%)$ & $35(42 \%)$ & $4(5 \%)$ \\
Dementia? & $34(41 \%)$ & $38(46 \%)$ & $11(13 \%)$ \\
Cases where disturbed mental state is a consequence of & & \\
$\quad$ physical illness or injury? & & \\
\hline
\end{tabular}

Similarly, $43(52 \%)$ stated that they would always detain an individual who was unable or unwilling to give clear consent to remaining in hospital on a voluntary basis.

Fifty-six (68\%) participants said that the power to enforce treatment should be extended to patients living in the community, but only to those who had a long history of refusing treatment, leading to deterioration in their mental state following discharge. One-third of those interviewed raised concerns about the feasibility of this and the potential for infringement of civil liberties.

\section{Comment}

Opinions about these selected areas of the legislation varied considerably. This presumably reflected quite marked differences in clinical practice. There was concern about current legal categories in the 1983 Act. A significant minority of participants expressed the wish for greater clarity of definition, and most thought that the current terms did not reflect the range of psychiatric disorders encountered in day-to-day clinical practice. Some were in favour of change in the law to include more specific terminology, such as that found elsewhere in the world (Mental Health Act New South Wales 1990). With the views expressed here about compulsory measures and their place in the care of patients with personality disorder, the continued use of the term 'psychopathic disorder' or inclusion of an alternative form of words should be reconsidered.

Provision for the treatment of conditions such as anorexia nervosa, dementia and disturbance of mental state due to physical illness or injury were considered inadequate. Despite the introduction of the Supervised Discharge Order (Mental Health (Patients in the Community) Act 1995), most respondents believed that the power to enforce treatment should be extended to some patients outside hospital.
The recent announcement of additional government funding to provide more assertive outreach and other intensive community support may alleviate concerns in this area, but it seemed clear that a significant majority of those interviewed were in favour of some sort of community treatment order.

The government has recently appointed the Mental Health Act Scoping Study Review Team to look at the content and extent of new legislation. Those interviewed here held quite different (and, in some cases, strong) views about particular areas of the current Act. This confirms the need for further, wider consultation before the law is substantively reformed, not only among medical practitioners but also among all those involved in the day-to-day care of mentally disordered people.

\section{Acknowledgements}

We thank those doctors who participated in this study. We are grateful to Mr John McDermott for advice on the interview questionnaire. The project was funded by South Birmingham Mental Health NHS Trust.

\section{References}

BLOM-COOPER, L., HALLY, H. \& MURPHY, E. (1995) The Falling Shadow. One Patient's Mental Health Care 1978 to 1993. London: Duckworth.

COPE, R. (1992) A survey of forensic psychiatrists views on psychopathic disorder. Joumal of Forensic Psychiatry. 4. 215-235.

EASTMAN, N. (1994) Mental Health Law: clvil liberties and the principle of reciprocity. British Medical Journal so8, 43-45.

HUMPHREYS, M. S. (1997) Non-consultant psychiatrists knowledge of emergency procedures in Scotland. Psychiatric Bulletin, 21, 631-635.

LAw Commission (1995) Report on Mental Incapacity. No. 231. London: HMSO.

MASON, T. \& JENNINGS, L. (1997) The Mental Health Act and professional hostage taking. Medicine. Science and the Law, 37, 58-68. 
Vijay Bhatti, Research Associate, Jeremy KenneyHerbert, Consultant Forensic Psychiatrist, Rosemarie Cope, Clinical Director and *Martin Humphreys, Senior Lecturer, Reaside Clinic,
Birmingham Great Park, Bristol Road South, Rubery, Birmingham B45 9BE

*Correspondence

\title{
Using the Health of the Nation Outcome Scales in clinical practice
}

\author{
Michael James and Robert Kehoe
}

\begin{abstract}
Aims and method To describe the implementation of a plan to use a validated outcome measure in the care and treatment of people with severe mental illness within a district general hospltal psychiatric service. Multiple techniques were necessary to promote actual change of practice.

Results A survey of practice found $77 \%$ of full Care Programme Approach patients to have recorded Health of the Nation Outcome Scales (HoNOS) scores in their care plans one year after the beginning of the implementation plan.

Clinical implications it is possible to incorporate the use of HoNOS in to everyday practice but it takes a lot of time, effort and resources. Mental health services may require a clearer indication from the NHS Executtive regarding the use of such outcome scales before committing themselves.
\end{abstract}

The first target of the Health of the Nation mental health strategy was to improve significantly the health and social functioning of mentally ill people (Department of Health, 1992). The Research Unit of the Royal College of Psychiatrists was commissioned to develop an outcome measure to determine such change and the result is a brief assessment tool that assesses physical, personal and social problems associated with mental illness, the Health of the Nation Outcome Scales (HoNOS; Wing et al, 1995). Mental health services have been encouraged by the College to use HoNOS as the standard outcome measure for people with enduring mental illness and HoNOS could be part of a 'minimum data set', if implemented throughout the National Health Service (NHS). HoNOS is already being used in health service research settings (Taylor \& Wilkinson, 1997) and is an integral part of other rating tools being developed such as CORE (Centre for Outcomes Research and Effectiveness; British Psychological Society, 1998).

\section{Using HoNOS in a local district service}

Airedale NHS Trust serves a mixed urban and rural population of 190000 across North and West Yorkshire. Locally, it was recognised by both purchasers and providers that there is a need to measure outcomes in mental health services. To consider the use of HoNOS within the Mental Health Directorate three members of staff attended a training day organised by the Royal College of Psychiatrists: a consultant psychiatrist, a community psychiatric nurse and a community mental health team leader. They would be the key players in planning. organising and delivering the training within the Directorate.

There was an acknowledgement that implementing the use of HoNOS was a long-term project, so a group was established to manage the process, consisting of a consultant psychiatrist, service manager and community mental health team leader.

Three phases were identified for rolling out the programme; training staff who were to carry out ratings, implementing the use of the scales and evaluating its use.

The plan produced by this project group was endorsed by the Directorate Management Group in early 1996 and responsibility for its implementation specified in a manager's objectives. It was recognised that its success required firm commitment from mental health staff, as well as collaborative working with social services. 